\title{
Outcomes and Risk Factors for Failed Trial of Labor After Cesarean Delivery (TOLAC) in Women with One Previous Cesarean Section: A Chinese Population-Based Study
}

\author{
Xiaobo He \\ Ningbo Women and Children's Hospital \\ Qiaona Dai \\ Ningbo Women and Children's Hospital \\ Xiaoli Wu \\ Ningbo Women and Children's Hospital \\ Junjun Zhou \\ Ningbo Women and Children's Hospital \\ Jie Li ( $\sim$ bingkuairongle@163.com ) \\ Ningbo Women and Children's Hospital
}

\section{Research Article}

Keywords: cesarean delivery, TOLAC, risk factor, VBAC, previous cesarean delivery

Posted Date: December 14th, 2021

DOI: https://doi.org/10.21203/rs.3.rs-1087096/v1

License: (c) (i) This work is licensed under a Creative Commons Attribution 4.0 International License.

Read Full License 


\section{Abstract \\ Background}

To evaluate the outcomes and risk factors for trial of labor after cesarean delivery (TOLAC) failure in patients in China.

\section{Methods}

Consecutive patients who had a previous cesarean delivery (CD) and were scheduled for TOLAC were included from 2014 to 2020 . Patients who successfully delivered were classified into the TOLAC success group. Patients who were scheduled for TOLAC and had a repeat CD due to medical issues were classified into the TOLAC failure group. Multiple logistic regression analyses were performed to examine the risk factors for TOLAC failure.

\section{Results}

In total, 720 women who had a previous CD and were scheduled for TOLAC were identified and included. The success rate of TOLAC was $84.17 \%$ (606/720). Seven patients were diagnosed with uterine rupture, none of whom underwent hysterectomy. Multiple logistic regression analysis showed that the gestational weeks at pregnancy termination (odds ratio $[\mathrm{OR}]=3.046,95 \%$ confidence interval [Cl]: 0.962-9.642, $\mathrm{P}=$ $0.005)$ and induction of labor $(\mathrm{OR}=2.843,95 \% \mathrm{Cl}: 1.571-5.145, \mathrm{P}=0.001)$ were positively associated with TOLAC failure. In contrast, the thickness of the lower uterine segment (LUS) (OR $=0.215,95 \% \mathrm{Cl}$ : $0.103-0.448, P=0.001)$ was negatively related to TOLAC failure.

\section{Conclusions}

This study suggests that TOLAC is effective in decreasing CD rates in the Chinese population. The gestational weeks at pregnancy termination and induction of labor were positively associated with TOLAC failure. Our findings need to be confirmed in larger samples with patients of different ethnicities.

\section{Background}

With the promotion of the two- and three-child policy, trial of labor after cesarean delivery (TOLAC) has been increasingly requested by women with a prior cesarean delivery (CD) in China [1]. Because of the high rate of CD in some cities in China [2], the accepted practice of TOLAC was approved by the government to lower the overall CD rates $[3,4]$. In the USA, these attempts were highly successful, and the rate of vaginal birth after cesarean delivery (VBAC) remained high from $34 \%$ in 1980 to a peak of $28.3 \%$ in 1996 and $20 \%-25 \%$ through 2009 [5]. There was a slight decrease because of widespread concerns about complications in TOLAC, including uterine rupture [6]. However, a systematic review of these 
complications by the National Institutes of Health $(\mathrm{NIH})$ indicated that TOLAC is a reasonable option for many women and has encouraged medical institutions to facilitate access to TOLAC $[7,8]$.

To the best of our knowledge, several factors have been identified that either increase or decrease the likelihood of successful TOLAC, including a previous vaginal delivery, a favorable cervix and obesity [9, 10]. These factors have been the focus of many studies from the USA and elsewhere, but close attention should be given to differences in study subjects and obstetrical practices among countries $[11,12]$. The rates of TOLAC, associated risk factors and outcomes in China remain unclear. In this study, we aimed to evaluate the success rate of TOLAC and the risk factors for TOLAC failure in patients in China, since this information will be essential for making appropriate clinical decisions.

\section{Methods}

\subsection{Patient identification}

This retrospective study was approved by the Institutional Review Board of Ningbo Women and Children's Hospital. The records/information of all women were anonymized and recorded before analysis due to the retrospective nature of the study. The study was conducted in accordance with the Declaration of Helsinki, and the protocol was approved by the Ethics Committee of Ningbo Women and Children's Hospital (approval number: [2017] Ethical review word (3) number).We analyzed maternal histories and delivery information by reviewing the medical and surgical records of delivery. All women who met the inclusion criteria between December 2014 and December 2020 were included in the study. The inclusion criteria were as follows: 1) singleton delivery; and 2) had a previous CD but was scheduled for TOLAC. The exclusion criteria were as follows: two or more previous CDs; twin pregnancy; contradictions to vaginal birth; history of other uterine incisions such as myomectomy; incomplete medical records; and patient request for repeat $C D$ during labor(Fig. 1.).

\subsection{Data collection}

The study examined demographic, obstetric, maternal, and delivery variables. These variables were chosen based on factors that were previously linked to TOLAC in other studies and their availability in our current clinical database. The demographic variables included age, body mass index, gravidity, parity, history of abortion; history of vaginal delivery, gestational weeks at pregnancy termination, estimated birth weight, time from previous CD, indication for previous CD (failed trial of labor) and lower uterine segment (LUS) thickness. The maternal and neonatal outcomes included blood loss during delivery, intrapartum blood transfusion, puerperal infection, NICU admission, Apgar score ( 5 min, $\leq 7$ ), injury to the bladder and incomplete or complete rupture of the muscle layer of the lower uterus. Prior to delivery or CD, the LUS thickness was assessed using an abdominal probe. Thickness was measured at the location of the LUS - above and below the refection of the urinary bladder. All measurements were taken in the absence of contractions. 
Induction of labor was then carried out using a transcervical Foley balloon catheter inflated with $70 \mathrm{ml}$ of $0.9 \%$ sodium chloride solution. After the balloon was expelled spontaneously or withdrawn after $24 \mathrm{~h}$, intravenous oxytocin was initiated according to the medical center's protocol.

\subsection{Statistical analysis}

The Mann-Whitney U test was used to examine continuous variables, and Fisher's exact test or chisquared test was used to examine categorical variables. Multiple logistic regression analyses were performed to identify the factors for TOLAC failure. All continuous predictors were assumed to be linearly associated with the outcome. Finally, a nomogram was built to estimate the probability of TOLAC, given the risk factors in the multivariable model. The accuracy of the logistic regression model was assessed graphically with a calibration curve by plotting the predicted probabilities of TOLAC on the x-axis and the observed probabilities of TOLAC on the y-axis. All statistical analyses were performed using SAS version 9.3 (SAS Institute, Inc., Cary, NC). Statistical significance was defined as $P<0.05$.

\section{Results}

During the study, 786 women who were scheduled for TOLAC were identified. Sixty-six participants who underwent repeat $\mathrm{CD}$ as requested by themselves or their family members rather than because of medical indications during labor delivery were excluded. The characteristics of all patients are shown in Table 1. The success rate of the TOLAC was $84.17 \%$ (606/720). No significant differences in age, body mass index, gravidity, parity, history of abortion, history of vaginal delivery, estimated birth weight, time from previous $C D$ and indication for previous $C D$ (failed trial of labor) were observed between the TOLAC success and TOLAC failure groups. The rate of induction of labor was significantly higher in the TOLAC failure group than in the TOLAC success group $(65.8 \%$ vs. $29.0 \%, P<0.01)$. The gestational weeks at pregnancy termination were significantly higher in the TOLAC failure group than in the TOLAC success group $(P<0.01)$. The LUS was significantly thinner in the TOLAC failure group than in the TOLAC success group $(P<0.01)$. The clinical outcomes are shown in Table 2 . 
Table 1

Demographic and clinical characteristics of the patients in the TOLAC success and failure groups

\begin{tabular}{|c|c|c|c|}
\hline Clinical parameters & $\begin{array}{l}\text { Success group } \\
(n=606)\end{array}$ & $\begin{array}{l}\text { Failure group } \\
(n=114)\end{array}$ & $\mathbf{P}$ \\
\hline Maternal age (years), & $31.31(17-40)$ & $31.56(18-41)$ & 0.769 \\
\hline $\mathrm{BMI}(\mathrm{kg} / \mathrm{m} 2)$ & $25.40 \pm 3.51$ & $25.63 \pm 4.61$ & 0.745 \\
\hline Gravidity, mean (range) & $2(0-9)$ & $3(0-9)$ & 0.065 \\
\hline Parity, mean (range) & $1(0-3)$ & $1(0-3)$ & \\
\hline Primipara, n (\%) & $492(81.19 \%)$ & $108(94.74 \%)$ & 0.006 \\
\hline Multipara, n (\%) & 114 (18.81\%) & $6(5.26 \%)$ & \\
\hline Number of abortions, mean (range) & $1(0-9)$ & $2(0-5)$ & 0.643 \\
\hline History of vaginal delivery (no), n (\%) & $489(80.69 \%)$ & $105(92.10 \%)$ & 0.093 \\
\hline $\begin{array}{l}\text { Gestational weeks at pregnancy termination, } \\
\text { (weeks) }\end{array}$ & $39.81 \pm 1.92$ & $40.71 \pm 2.65$ & 0.001 \\
\hline Induction of labor (yes), n (\%) & $176(29.04 \%)$ & $75(65.79 \%)$ & 0.001 \\
\hline Estimated birth weight $(\mathrm{kg})$ & $3.28(2.84-3.50)$ & $3.35(3.14-3.66)$ & 0.046 \\
\hline Time from previous CD (years) & $6.01(4.12-8.13)$ & $6.33(4.39-7.23)$ & 0.642 \\
\hline $\begin{array}{l}\text { Indication for the previous CD (failed trial of } \\
\text { labor), } \mathrm{n}(\%)\end{array}$ & $101(16.80 \%)$ & $24(21.12 \%)$ & 0.534 \\
\hline LUS thickness, mm & $22 \pm 11$ & $17 \pm 10$ & 0.001 \\
\hline
\end{tabular}


Table 2

Clinical outcomes of the patients

\begin{tabular}{|llll|}
\hline Clinical outcomes & $\begin{array}{l}\text { Success group } \\
(\mathbf{n = 6 0 6 )}\end{array}$ & $\begin{array}{l}\text { Failure group } \\
(\mathbf{n = 1 1 4})\end{array}$ & $\mathbf{P}$ \\
\hline Blood loss during delivery $(\mathrm{ml})$ & $300 \pm 52$ & $500 \pm 60$ & 0.001 \\
\hline Intrapartum blood transfusion, $\mathrm{n}(\%)$ & $0(0)$ & $3(2.63 \%)$ & 0.001 \\
\hline Puerperal infection, $\mathrm{n}(\%)$ & $3(0.50 \%)$ & 0 & 0.001 \\
\hline NICU admission, $\mathrm{n}(\%)$ & $96(15.84 \%)$ & $6(5.31 \%)$ & 0.001 \\
Apgar score(5 min, $\leq 7), \mathrm{n}(\%)$ & $12(2.00 \%)$ & 0 & 0.001 \\
\hline $\begin{array}{l}\text { Incomplete or complete rupture of the muscle } \\
\text { layer of the }\end{array}$ & $6(0.99 \%)$ & 0 & 0.001 \\
lower uterus, $\mathrm{n}(\%)$ & & & \\
\hline Injury to the bladder, $\mathrm{n}(\%)$ & 0 & 0 & \\
\hline
\end{tabular}

The outcome indicators in the TOLAC failure and success groups are presented in Table 2 . There were 7 patients who had incomplete or complete rupture of the muscle layer of the lower uterus in the success group (rupture of the uterus). There were no significant differences in puerperal infection, bladder injury, or 5-min Apgar scores between the two groups. The volume of blood loss during delivery and the incidence of blood transfusion during delivery in the TOLAC success group were significantly lower than those in the TOLAC failure group. The rate of NICU admission was significantly higher in the success group than in the TOLAC failure group $(P=0.001)$.

Multiple logistic regression analysis showed that gestational weeks at pregnancy termination (odds ratio $[\mathrm{OR}]=3.046,95 \%$ confidence interval $[\mathrm{Cl}]: 0.962-9.642, \mathrm{P}=0.005)$ and induction of labor $(\mathrm{OR}=2.843,95 \%$ Cl: $1.571-5.145, P=0.001)$ were positively associated with TOLAC failure. In contrast, the thickness of the LUS (OR $=0.215,95 \% \mathrm{Cl}: 0.103-0.448, p=0.001)$ was negatively related to TOLAC failure (Table 3 ).

Table 3

Multiple regression logistic using LASSO to identify the predictive factors for TOLAC failure in women

\begin{tabular}{|llll|}
\hline & OR & $95 \%$ Cl & P \\
\hline Gestational weeks at pregnancy termination & 3.046 & $0.962-9.642$ & 0.005 \\
\hline Induction of labor (yes) & 2.843 & $1.571-5.145$ & 0.001 \\
\hline LUS thickness & 0.215 & $0.103-0.448$ & 0.001 \\
\hline OR, odds ratio; Cl, confidence interval. & & & \\
\hline
\end{tabular}




\section{Discussion}

This study showed that TOLAC is safe and feasible for most patients who had a prior CD in our hospital. The success rate of TOLAC was $84.17 \%$, which was similar to the rates in other regions in China $(76.48 \%$ in Xi'an [10] and 84\% in Guangdong [13]). The success rate of TOLAC was $88.6 \%$ in Japan and $91.3 \%$ in reported studies, which are higher than the rate we observed $[12,14]$. Compared with the TOLAC failure group, the patients in the TOLAC success group had a lower volume of blood loss, lower blood transfusion rate and lower NICU admission rate. In general, TOLAC is a potential strategy for decreasing the $C D$ rate, and successful trials of labor could reduce the incidence of some important adverse outcomes.

Uterine rupture is a serious complication of TOLAC. The incidence of this complication among women who attempted TOLAC in the present study was $0.97 \%(7 / 720)$. Another study reported that the rate of uterine rupture was 1.0 to $4.2 \%$ [15-17]. Five patients were diagnosed with hematoma around the uterine scar by ultrasound, and they all recovered after conservative treatment. Two patients had been found omentum majus in the vagina and underwent emergency laparotomy and uterine repair. None of these patients underwent a hysterectomy. In a previous study, the rate of hysterectomy in patients who were scheduled for TOLAC was 3.2/1 000 [18].

A univariate analysis revealed that the rate of induction of labor was significantly lower in the TOLAC success group than in the TOLAC failure group. Multiple logistic regression analysis showed that induction of labor was positively associated with TOLAC failure. Cohort studies conducted in India and Thailand also showed that labor induction was independently associated with failed $\operatorname{TOLAC}[9,19]$. The most common method of induction in our hospital is the use of a Foley balloon to ripen the cervix. Compared with an unfavorable cervix, a favorable cervix or dilated cervix was more likely to achieve a vaginal delivery. Choosing the best method to ripen the cervix could double the rate of successful TOLAC with half the effort.

In this study, the thickness of the LUS (OR $=0.215,95 \% \mathrm{Cl}: 0.103-0.448, \mathrm{P}=0.001)$ was negatively related to TOLAC failure, meaning that if the LUS is thicker, the opportunity for successful TOLAC is lower, which was similar to the results of Emmanuel's study [20]. However, some studies have observed different results, noting that the thickness of the uterine scar was not related to the success of TOLAC [21-23]. A possible reason for this difference is that the accuracy of B-ultrasound in evaluating the thickness and continuity of the uterine scar myometrium is still controversial [24]. However, based on our study, pregnant women with a thickened LUS who are not suitable for TOLAC should undergo elective repeat cesarean delivery (ERCD).

However, this study did not find any significant difference in the rate of successful TOLAC between groups with regard to indications for previous CD (failed trial of labor), time from previous CD or history of vaginal delivery. Unfortunately, the literature consistently shows that women who have delivered vaginally in the past achieve successful VBACs at a much higher rate (almost a 3-fold difference) than 
women without a prior vaginal delivery $[25,26]$. However, studies are needed to address the implications of these factors.

There are several limitations to this study. First, this study was retrospective with a small number of cases from a single center. Second, many women who would be good candidates for TOLAC still choose ERCD, making the success of TOLAC unconvincing. Further randomized, controlled trials and multicenter studies are required in the future. Third, all patients in this study were Chinese. Further studies in other populations are required to confirm our findings. Finally, data on several confounding factors, such as tobacco use, alcohol consumption, nutritional status, and socioeconomic conditions, were not available in this study, which might have led to an overestimation of the TOLAC rate. Therefore, our results should be interpreted with caution.

\section{Conclusions}

Our study adds to the limited evidence that TOLAC is effective in decreasing CD rates in the Chinese population. The gestational weeks at pregnancy termination and induction of labor were positively associated with TOLAC failure. Our findings need to be confirmed in larger samples with patients of different ethnicities.

\section{Declarations}

Ethics approval and consent to participate: This study was conducted in accordance with the Declaration of Helsinki and was approved by the Ethnic Committee of the Ningbo Women and Children's Hospital(Number: IRB-[2017] Ethical review word (3) number). All data were collected from the electronic medical record system in the department of Obstetrics Medicine Center. Data were anonymized and deidentified before analysis. The Ethnic Committee of the Ningbo Women and Children's Hospital(Number: IRB-[2017] Ethical review word (3) number) provided a waiver of written informed consent for this study.

Consent for publication Not applicable.

\section{Availability of data and materials}

The datasets generated and/or analysed during the current study are available in Clinical trial registration: researchregistry7416 ( https://www.researchregistry.com/registernow\#home/registrationdetails/61a68ec6e1410e0020396cdb/)

Competing interests: The authors declare no conflict of interest.

Funding: This study was supported by Medical Science and Technology Project of Zhejiang Province (2018KY715).

Authors' contributions: XBH: Data Collection, Manuscript Writing; QND and JJZ: Data Collection, XLW: Data Analysis; JL: Project Development, Manuscript Editing. All the authors reviewed and approved the 
final version of the manuscript.

Acknowledgements: We would like to express my gratitude to all those who helped me during the writing of this manuscript. Thanks to all the peer reviewers for their opinions and suggestions.

\section{References}

1. Li HT, Xue M, Hellerstein S, Cai Y, Gao Y, Zhang Y, et al. Association of China's universal two child policy with changes in births and birth related health factors: national, descriptive comparative study. BMJ. 2019;366:L4680.

2. Yan J, Wang L, Yang Y, Zhang Y, Zhang H, He Y, et al. The trend of caesarean birth rate changes in China after 'universal two-child policy' era: a population-based study in 2013-2018. BMC Med. 2020;18:249.

3. Liu X, Lynch CD, Cheng WW, Landon MB. Lowering the high rate of caesarean delivery in China: an experience from Shanghai. BJOG. 2016;123:1620-8.

4. Fan H, Gu H, You H, Xu X, Kou Y, Yang N. Social determinants of delivery mode in Jiangsu, China. BMC Pregnancy Childbirth. 2019;19:473.

5. Sabol B, Denman MA, Guise JM. Vaginal birth after cesarean: an effective method to reduce cesarean. Clin Obstet Gynecol. 2015;58:309-19.

6. Zweifler J, Garza A, Hughes S, Stanich MA, Hierholzer A, Lau M. Vaginal birth after cesarean in California: before and after a change in guidelines. Ann Fam Med. 2006;4:228-34.

7. ACOG Practice Bulletin No. 205: vaginal birth after cesarean delivery. Obstet Gynecol. 2019;133:e11027.

8. Leeman LM, King VJ. Increasing patient access to VBAC: new NIH and ACOG recommendations. Am Fam Physician. 2011;83:121-2, 127.

9. Parveen S, Rengaraj S, Chaturvedula L. Factors associated with the outcome of TOLAC after one previous caesarean section: a retrospective cohort study. J Obstet Gynaecol. 2021. doi:10.1080/01443615.2021.1916451.1-7.

10. Mi Y, Qu P, Guo N, Bai R, Gao J, Ma Z, et al. Evaluation of factors that predict the success rate of trial of labor after the cesarean section. BMC Pregnancy Childbirth. 2021;21:527.

11. Harris BS, Heine RP, Park J, Faurot KR, Hopkins MK, Rivara AJ, et al. Are prediction models for vaginal birth after cesarean accurate? Am J Obstet Gynecol. 2019;220:492.e1-.e7.

12. Takeya A, Adachi E, Takahashi Y, Kondoh E, Mandai M, Nakayama T. Trial of labor after cesarean delivery (TOLAC) in Japan: rates and complications. Arch Gynecol Obstet. 2020;301:995-1001.

13. Li YX, Bai Z, Long DJ, Wang HB, Wu YF, Reilly KH, et al. Predicting the success of vaginal birth after caesarean delivery: a retrospective cohort study in China. BMJ Open. 2019;9:e027807.

14. Uno K, Mayama M, Yoshihara M, Takeda T, Tano S, Suzuki T, et al. Reasons for previous cesarean deliveries impact a woman's independent decision of delivery mode and the success of trial of labor 
after cesarean. BMC Pregnancy Childbirth. 2020;20:170.

15. Tanos V, Toney ZA. Uterine scar rupture - prediction, prevention, diagnosis, and management. Best Pract Res Clin Obstet Gynaecol. 2019;59:115-31.

16. O'Brien-Abel N. Uterine rupture during VBAC trial of labor: risk factors and fetal response. J Midwifery Womens Health. 2003;48:249-57.

17. Holmgren CM. Uterine rupture associated with VBAC. Clin Obstet Gynecol. 2012;55:978-87.

18. Landon MB, Hauth JC, Leveno KJ, Spong CY, Leindecker S, Varner MW, et al. Maternal and perinatal outcomes associated with a trial of labor after prior cesarean delivery. N Engl J Med. 2004;351:25819.

19. Thapsamuthdechakorn A, Sekararithi R, Tongsong T. Factors associated with successful trial of labor after cesarean section: a retrospective cohort study. J Pregnancy. 2018;2018:6140982.

20. Bujold E, Jastrow N, Simoneau J, Brunet S, Gauthier RJ. Prediction of complete uterine rupture by sonographic evaluation of the lower uterine segment. Am J Obstet Gynecol. 2009;201:320.e1-6.

21. Schmitz J, Stepan H, Schrey-Petersen S, Hoffmann J. Does lower uterine segment thickness measurement improve birth planning after previous cesarean section? Z Geburtshilfe Neonatol. 2019;223:350-8.

22. Spiegel E, Weintraub AY, Aricha-Tamir B, Ben-Harush Y, Hershkovitz R. The use of sonographic myometrial thickness measurements for the prediction of time from induction of labor to delivery. Arch Gynecol Obstet. 2021;303:891-6.

23. Sen S, Malik S, Salhan S. Ultrasonographic evaluation of lower uterine segment thickness in patients of previous cesarean section. Int J Gynaecol Obstet. 2004;87:215-9.

24. Sanlorenzo O, Farina A, Pula G, Zanello M, Pedrazzi A, Martina T, et al. Sonographic evaluation of the lower uterine segment thickness in women with a single previous cesarean section. Minerva Ginecol. 2013;65:551-5.

25. Wingert A, Hartling L, Sebastianski M, Johnson C, Featherstone R, Vandermeer B, et al. Clinical interventions that influence vaginal birth after cesarean delivery rates: systematic review \& metaanalysis. BMC Pregnancy Childbirth. 2019;19:529.

26. Lehmann S, Baghestan E, Børdahl PE, Irgens LM, Rasmussen S. Low risk pregnancies after a cesarean section: determinants of trial of labor and its failure. PLoS One. 2020;15:e0226894.

\section{Figures}




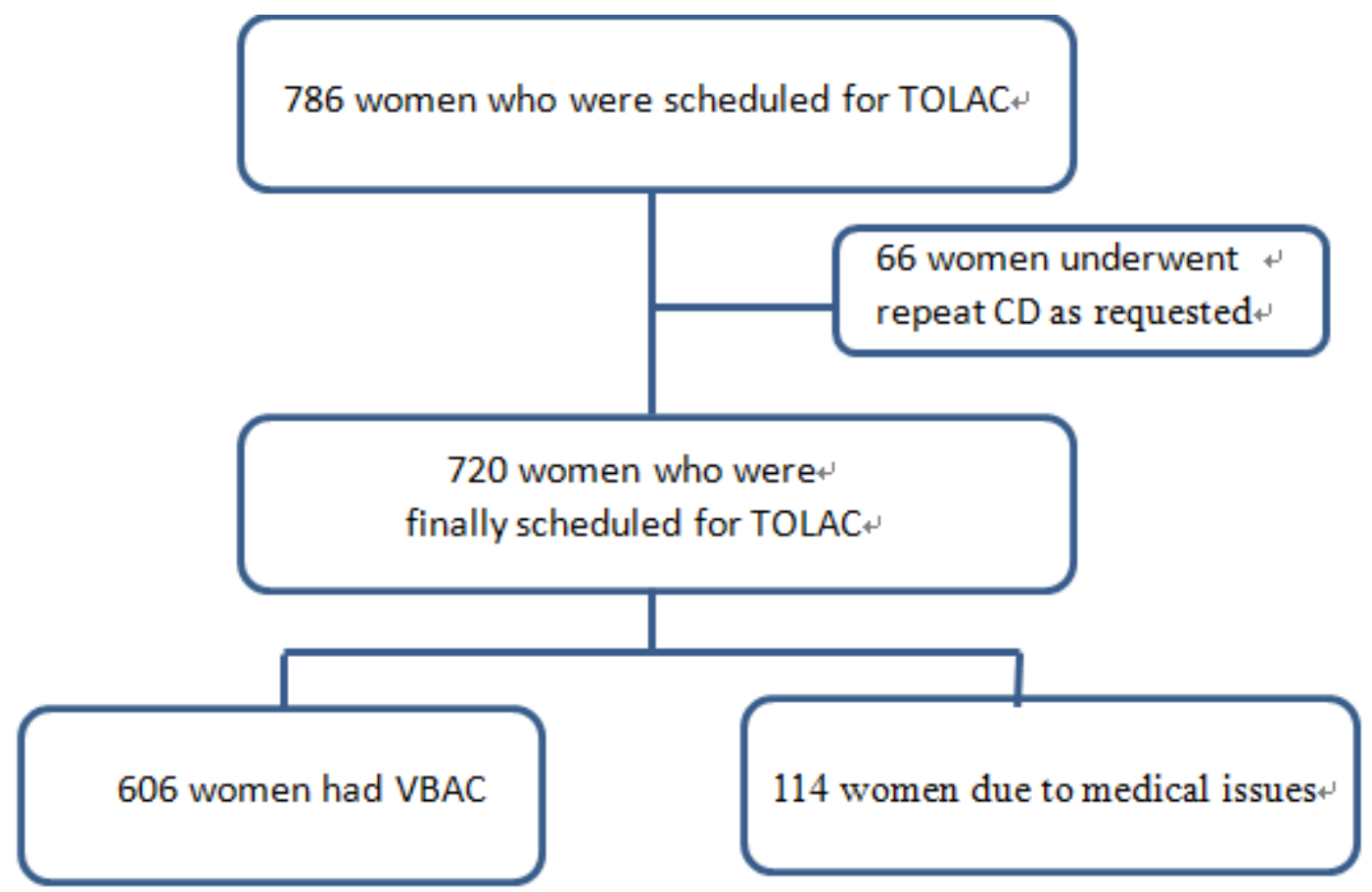

\section{Figure 1}

Flow diagram of patient selection. $C D=$ cesarean delivery, $T O L A C=$ trial of labor after cesarean delivery, VBAC = vaginal birth after cesarean delivery . 